\title{
A constituição das teorias pedagógicas da educação física
}

\author{
Valter Bracht*
}

RESUMO: O presente ensaio analisa o processo de construção das teorias pedagógicas da educação física no Brasil, buscando demonstrar como elas refletem a concepção e o significado humano de corpo engendrados na e pela sociedade moderna. O texto apresenta as teorias pedagógicas que no âmbito da educação física se colocam numa perspectiva crítica em relação aos usos e aos significados atribuídos pela sociedade capitalista às práticas corporais. $\mathrm{E}$, finalmente, problematiza a possibilidade de estarmos diante de uma ruptura da visão moderna de corpo, refletindo sobre os desafios que essa transição coloca para a educação/educação física.

Palavras-chave: Educação física, corpo, modernidade, pós-modernidade

\section{Educação "corporal" no âmbito da educação física}

Neste primeiro item, desejamos apresentar as categorias e as problematizações básicas que orientaram nossas reflexões sobre o tema. Elas são derivadas de questões como: do ponto de vista educativo, o que tem significado a educação "corporal"? Que tipo de educação "corporal" a escola e a educação física vêm realizando? Por que surge o interesse pela educação "corporal" (também na escola) e quais suas determinações sócio-históricas?

\footnotetext{
* Professor de Educação Física do Centro de Educação Física e Desportos da Universidade
} Federal do Espírito Santo. 
A utilização de aspas na expressão educação "corporal" fornece uma pista de uma das questões que pretendemos colocar. A tradição racionalista ocidental tornou possível falar confortavelmente da possibilidade de uma educação intelectual, por um lado, e de uma educação física ou corporal, por outro, quando não de uma terceira educação, a moral - expressão da razão cindida das três críticas de I. Kant, filósofo que, não obstante, segundo Welsch (1988), preocupou-se intensamente com as mediações entre as diferentes dimensões da racionalidade. Essas educações teriam alvos, objetos bem distintos: o espiritual ou mental (o intelecto), por um lado, e o corpóreo ou físico, por outro, resultando da soma a educação integral (educação intelectual, moral e física). É claro, o alvo era ou é o comportamento humano, mas influenciá-lo ou conformá-lo pode ser alcançado pela ação sobre o intelecto e sobre o corpo. Também na melhor tradição ocidental, a educação "corporal" vai pautar-se pela idéia, culturalmente cristalizada, da superioridade da esfera mental ou intelectual a razão como identificadora da dimensão essencial e definidora do ser humano. O corpo deve servir. O sujeito é sempre razão, ele (o corpo) é sempre objeto; a emancipação é identificada com a racionalidade da qual o corpo estava, por definição, excluído. ${ }^{1}$

A esse respeito, assim se expressa Santin (1994, p. 13):

A racionalidade foi proclamada como a especificidade exclusiva e única das dimensões humanas. O humano do homem ficou enclausurado nos limites da racionalidade. Ser racional e ter o uso da razão constituíram-se nos únicos pressupostos para assegurar os plenos direitos de pertencer à humanidade.

Ou, como afirma Gil (1994) em seu brilhante Monstros, referindose à visão de corpo-máquina:

Deu-se uma transferência dos poderes do corpo para o espírito: de nada serve ao corpo estar substancialmente unido ao espírito (e, assim, tornar-se vivo e indivisível), é este último que define a sua natureza humana. Doravante, o único defeito do corpo é poder levar a alma a enganar-se. (p. 169)

As teorias ou metanarrativas que circunstanciam o projeto da modernidade e que projetavam perspectivas para a humanidade não 
reservavam ao corpo (a seus desejos, suas fantasias etc.) papel central. Não lhe atribuíam papel importante para a construção de uma prática emancipatória, como também nenhum papel subversivo. A emancipação humana (iluminista) dar-se-ia pela razão, pela consciência desencarnada. As teorias da consciência, mesmo as de orientação positivista, são mentalistas - vai ser a psicanálise, que não casualmente não goza de grande prestígio acadêmico, que colocará o corpóreo, a dimensão não-racionalizada, como elemento importante para o entendimento das ações humanas.

Nas teorias do conhecimento da modernidade, que têm sua expressão máxima no chamado método científico (a ciência moderna), o corpo ou a dimensão corpórea do homem aparece como um elemento perturbador que precisa ser controlado pelo estabelecimento de um procedimento rigoroso (por exemplo: Francis Bacon e os idola).

Para Veiga Neto (1996), se existe alguma culpa na ciência ou na racionalidade moderna, ela se situa na divisão entre res estensa e res cogitans, pois essa separação fundamentou o nosso afastamento em relação ao resto do mundo. Esse afastamento, segundo o autor, deixa-nos sem compromisso com o destino de tudo o que nos cerca, incluindo aí os outros homens e mulheres. Tal separação está na base da idéia do controle racional do mundo.

Tanto as teorias da construção do conhecimento como as teorias da aprendizagem, com raras exceções, são desencarnadas - é o intelecto que aprende. Ou então, depois de uma fase de dependência, a inteligência ou a consciência finalmente se liberta do corpo. Inclusive as teorias sobre aprendizagem motora são em parte cognitivistas. O papel da corporeidade na aprendizagem foi historicamente subestimado, negligenciado. Hoje é interessante perceber um movimento no sentido de recuperar a "dignidade" do corpo ou do corpóreo no que diz respeito aos processos de aprendizagem. Isso acontece, curiosamente, por intermédio dos desenvolvimentos nas ciências naturais (ver a respeito Assmann 1996).

Mas claro que esse entendimento de ser humano tem bases concretas na forma como o homem vem produzindo e reproduzindo a vida. Nesse sentido, o corpo sofre a ação, sofre várias intervenções com a finalidade de adaptá-lo às exigências das formas sociais de organização da produção e da reprodução da vida. Alvo das necessidades produtivas (corpo produtivo), das necessidades sanitárias (corpo "saudável"), das necessidades morais (corpo deserotizado), das necessidades de adaptação e 
controle social (corpo dócil). O déficit de dignidade do corpo vinha de seu caráter secundário perante a força emancipatória do espírito ou da razão. Mas esse mesmo corpo, assim produzido historicamente, repunha a necessidade da produção de um discurso que o secundarizava, exatamente porque causava um certo mal-estar à cultura dominante. Ele precisa, assim, ser alvo de educação, mesmo porque educação corporal é educação do comportamento que, por sua vez, não é corporal, e sim humano. Educar o comportamento corporal é educar o comportamento humano.

Mas vejamos na trajetória das diferentes construções históricas da educação física (EF) como esse entendimento de corpo e de educação corporal se concretizou. Antes é imprescindível fazer uma observação quanto a um equívoco que grassa no âmbito da educação física. Tratase do entendimento de que a educação corporal ou o movimento corporal é atribuição exclusiva da educação física. Sem dúvida, à educação física é atribuída uma tarefa que envolve as atividades de movimento que só pode ser corporal, uma vez que humano. No entanto, a educação do comportamento corporal, porque humano, acontece também em outras instâncias e em outras disciplinas escolares.

Contudo, neste texto vou me concentrar na contribuição da disciplina educação física (EF) para a "educação corporal" que acontece na escola, portanto, na construção das teorias pedagógicas da EF. Mas é importante observar que na instituição escolar o termo disciplina envolve um duplo aspecto: por um lado, a dimensão das relações hierárquicas, observância de preceitos, normas, da conduta do corpo; por outro, os aspectos do conhecimento propriamente dito. Portanto, a escola promove a "educação corporal". Nos dizeres de Faria Filho (1997, p. 52): "Assim como a escola 'escolarizou' conhecimentos e práticas sociais, buscou também apropriarse de diversas formas do corpo e constituir uma corporeidade que lhe fosse mais adequada". Esse aspecto reveste-se de importância, uma vez que o tratamento do corpo na EF sofre influências externas da cultura de maneira geral, mas também internas, ou seja, da própria instituição escolar.

\section{Da origem médica e militar à esportivização}

A constituição da educação física, ou seja, a instalação dessa prática pedagógica na instituição escolar emergente dos séculos XVIII e XIX, foi fortemente influenciada pela instituição militar e pela medicina. A instituição 
militar tinha a prática - exercícios sistematizados que foram ressignificados (no plano civil) pelo conhecimento médico. Isso vai ser feito numa perspectiva terapêutica, mas principalmente pedagógica. Educar o corpo para a produção significa promover saúde e educação para a saúde (hábitos saudáveis, higiênicos). Essa saúde ou virilidade (força) também pode ser (e foi) ressignificada numa perspectiva nacionalista/patriótica. Há exemplos marcantes na história desse tipo de instrumentalização de formas culturais do movimentar-se, como, por exemplo, a ginástica: Jahn e Hitler na Alemanha, Mussolini na Itália e Getúlio Vargas e seu Estado Novo no Brasil. Esses movimentos são signatários do entendimento de que a educação da vontade e do caráter pode ser conseguida de forma mais eficiente com base em uma ação sobre o corpóreo do que com base no intelecto; lá, onde o controle do comportamento pela consciência falha, é preciso intervir no e pelo corpóreo (o exemplo mais recente é o movimento carismático da Igreja Católica no Brasil - a aeróbica do Senhor). Normas e valores são literalmente "incorporados" pela sua vivência corporal concreta. A obediência aos superiores precisa ser vivenciada corporalmente para ser conseguida; é algo mais do plano do sensível do que do intelectual.

O corpo é alvo de estudos nos séculos XVIII e XIX, fundamentalmente das ciências biológicas. O corpo aqui é igualado a uma estrutura mecânica - a visão mecanicista do mundo é aplicada ao corpo e a seu funcionamento. O corpo não pensa, é pensado, o que é igual a analisado (literalmente, "lise") pela racionalidade científica. Ciência é controle da natureza e, portanto, da nossa natureza corporal. A ciência fornece os elementos que permitirão um controle eficiente sobre o corpo e um aumento de sua eficiência mecânica. ${ }^{2}$ Melhorar o funcionamento dessa máquina depende do conhecimento que se tem de seu funcionamento e das técnicas corporais que construo com base nesse conhecimento.

Assim, o nascimento da EF se deu, por um lado, para cumprir a função de colaborar na construção de corpos saudáveis e dóceis, ou melhor, com uma educação estética (da sensibilidade) que permitisse uma adequada adaptação ao processo produtivo ou a uma perspectiva política nacionalista, e, por outro, foi também legitimado pelo conhecimento médico-científico do corpo que referendava as possibilidades, a necessidade e as vantagens de tal intervenção sobre o corpo. Como lembra Le Breton (1995), a medicina representa, em nossas sociedades, um saber em alguma medida oficial sobre o corpo.

Mas novamente esse entendimento vai se alterar e mais uma vez em consonância com alterações de ordem mais geral, ou seja, da forma 
como se produz e reproduz a vida, portanto, de mudanças históricas. Foucault (1985) identifica uma mudança importante da ação do poder ou do envolvimento do corpo pelos/nos micropoderes. Paulatinamente no século XX saímos de um controle do corpo via racionalização, repressão, com enfoque biológico, para um controle via estimulação, enaltecimento do prazer corporal, com enfoque psicológico. Muitos estudos citam a década de 1960 (Courtine 1996; Le Breton 1995) como o momento mais importante dessa inflexão. Voltaremos a isso mais adiante.

Outro fenômeno muito importante para a política do corpo foi gestado e adquiriu grande significação social nesse período histórico (séculos XIX e XX). Essa prática corporal, a esportiva, está desde cedo muito fortemente orientada pelos princípios da concorrência e do rendimento (Rigauer 1969). Este último aspecto ou esta última característica é comum a outra técnica corporal incentivada pelos filantropos e pela medicina na Europa continental que é a ginástica. Aumento do rendimento atlético-esportivo, com o registro de recordes, é alcançado com uma intervenção científico-racional sobre o corpo que envolve tanto aspectos imediatamente biológicos, como aumento da resistência, da força etc., quanto comportamentais, como hábitos regrados de vida, respeito às regras e normas das competições etc. Treinamento esportivo e ginástica promovem a aptidão física e suas conseqüências: a saúde e a capacidade de trabalho/rendimento individual e social, objetivos da política do corpo. A ginástica é parte importante do movimento médico-social do higienismo, como mostrou Soares (1997).

Interessante observar que Foucault (1985, p. 151), quando perguntado sobre quem coordena a ação dos agentes da política do corpo, afirma que é "um conjunto extremamente complexo (...). Tomemos o exemplo da filantropia no início do século XIX: pessoas que vêm se ocupar da vida dos outros, de sua saúde, da alimentação, da moradia... Mais tarde, dessa função confusa saíram personagens, instituições, saberes... uma higiene pública, inspetores, assistentes sociais, psicólogos. E hoje assistimos a uma proliferação de categorias de trabalhadores sociais". Entre estes, seguramente podemos situar os professores de EF.

Interessante observar que a adesão ao esporte na Inglaterra puritana, segundo Grieswelle (1978), deveu-se também ao fato de este ter incorporado o princípio do rendimento que o aproximou da ética do trabalho, propiciando inclusive a construção do conceito de "Cristandade Muscular". Courtine (1995) mostra de forma brilhante como o puritanis- 
mo absorve esse tipo de prática corporal nos Estados Unidos, conferindo-Ihe um significado coerente com a doutrina religiosa e com os valores culturais dominantes.

A emergência do esporte após a Guerra Civil ocorreu sobre o pano de fundo de um individualismo disciplinado, exigindo auto-sacrifício e devotamento a uma causa comum. A ética puritana do trabalho tinha se infiltrado profundamente nas práticas esportivas, como se a utilidade social destas práticas devesse ser julgada apenas de acordo com seu critério. Entretanto, no final do século XIX, esta lógica de organização racional e de ordem moral já estava em declínio. Durante as primeiras décadas deste século, ela foi sendo progressivamente substituída por uma concepção um tanto diferente das finalidades da cultura física. O espírito de competição, o desejo de vencer tinham, mais ainda que no passado, sido investidos pelo esporte, ao mesmo tempo em que invadiam o sentimento de que se podia legitimamente buscar no exercício muscular uma gratificação pessoal e um prazer do corpo. Um cuidado com o bem-estar individual aparece nas críticas da ética puritana formuladas desde então. Reprova-se essa ética por investir a totalidade da energia do indivíduo americano em fins puramente utilitaristas, por exprimir e mesmo reforçar um medo do prazer. (Courtine 1995, p. 99)

É claro que o esporte, assim como a ginástica, é um fenômeno polissêmico, ou seja, apresenta vários sentidos/significados e ligações sociais. Por exemplo, o movimento olímpico permitiu conferir, pela categoria política da nação, um significado mais imediatamente político aos resultados esportivos, o qual é incorporado à política do corpo mais geral, com as repercussões que todos conhecemos na educação física. Chamo aqui a atenção para a combinação de dois fatores, e para o fato de que o esporte passa a substituir, com vantagens, a ginástica como técnica corporal que corporifica/condensa os princípios que precisam ser incorporados (no duplo sentido) pelos indivíduos.

A pedagogia da EF incorporou, sem necessidade de mudar seus princípios mais fundamentais, essa "nova" técnica corporal, o esporte, agregando agora, em virtude das intersecções sociais (principalmente políticas) desse fenômeno, novos sentidos/significados, como, por exemplo, preparar as novas gerações para representar o país no campo es- 
portivo (internacional). Tal combinação de objetivos fica muito clara no conhecido Diagnóstico da Educação Física/Desportos, realizado pelo governo brasileiro e publicado em 1971 (Costa 1971).

Como os princípios eram os mesmos e o núcleo central era a intervenção no corpo (máquina) com vistas ao seu melhor funcionamento orgânico (para o desempenho atlético-esportivo ou desempenho produtivo), o conhecimento básico/privilegiado que é incorporado pela EF para a realização de sua tarefa continua sendo o que provém das ciências naturais, mormente a biologia e suas mais diversas especialidades, auxiliadas pela medicina, como uma de suas aplicações práticas.

\section{Os anos 80 e a crítica ao "paradigma da aptidão física e esportiva"}

O paradigma que orientou a prática pedagógica em EF descrito no item anterior esteve presente desde a origem e durante a implementação no Brasil, e foi revitalizado pelo projeto de nação da ditadura militar que aqui se instalou a partir de 1964. Pelo Diagnóstico da EF/Desportos, anteriormente citado, e pelos documentos da política de desenvolvimento dos esportes e da educação, aliás, extremamente abundantes nesse período, fica claro que a EF (no sentido lato) possuía um papel importante no projeto de Brasil dos militares, e que tal importância estava ligada ao desenvolvimento da aptidão física e ao desenvolvimento do desporto: a primeira, porque era considerada importante para a capacidade produtiva da nação (da classe trabalhadora) - ver a esse respeito Gonçalves (1971) -, e o segundo, pela contribuição que traria para afirmar o país no concerto das nações desenvolvidas (Brasil potência) e pela sua contribuição para a primeira, ou seja, para a aptidão física da população. É claro que no percurso da hegemonia desse paradigma ele foi contestado, alternativas foram propostas; no entanto, nada que pudesse abalar seriamente seus princípios. No seio da própria instituição militar, que teve forte influência na trajetória da EF brasileira, muitos de seus intelectuais foram influenciados nas décadas de 1920 a 1950 pelo movimento escolanovista e pensaram a educação e a educação física com base nos princípios dessa teoria pedagógica. ${ }^{3}$

Neste ponto aproveito para abordar um outro equívoco recorrente na área da EF. O de que o predomínio do conhecimento das ciências naturais, principalmente da biologia e seus derivados, como conheci- 
mento fundamentador da EF, significava a ausência da reflexão pedagógica. Ao contrário, como procurei demonstrar em estudo anterior (Bracht 1996), até o advento das ciências do esporte nos anos 70 , o teorizar no âmbito da EF era sobretudo de caráter pedagógico, isto é, voltado para a intervenção educativa sobre o corpo; é claro, sustentado fundamentalmente pela biologia. Falava-se na educação integral (o famoso caráter biopsicossocial), mas como a educação integral não legitima especificamente a EF na escola (ou na sociedade) e sim o seu específico, este era entendido na perspectiva de sua contribuição para o desenvolvimento da aptidão física e esportiva.

A entrada mais decisiva das ciências sociais e humanas na área da EF, processo que tem vários determinantes, permitiu ou fez surgir uma análise crítica do paradigma da aptidão física. Mas esse viés encontrase num movimento mais amplo que tem sido chamado de movimento renovador da EF brasileira na década de 1980 .

Um primeiro momento dessa crítica tinha um viés cientificista. Por esse viés, entendia-se que faltava à EF ciência. Era preciso orientar a prática pedagógica com base no conhecimento científico, este, por sua vez, entendido como aquele produzido pelas ciências naturais ou com base em seu modelo de cientificidade. O desconhecimento da história da EF fez com que não se percebesse que esse movimento apenas atualizava o percurso e a origem histórica da EF e, portanto, que ele não rompia com o próprio paradigma da aptidão física. Nesse período vamos assistir à entrada em cena também de outra perspectiva que é aquela que se baseia nos estudos do desenvolvimento humano (desenvolvimento motor e aprendizagem motora). O segundo momento vai permitir, então, uma crítica mais radical à $E F$, como veremos a seguir.

A partir da década de 1970, no mundo e no Brasil, passa a constituir-se mais claramente um campo acadêmico na/da EF, campo este que se estrutura a partir das universidades (entre outros, ver Sobral 1996, pp. 243-252, e Bracht 1996), em grande medida em virtude da importância da instituição esportiva, já em simbiose com a EF. O discurso (neo)cientificista da EF visava também à legitimação desta no âmbito universitário.

A educação física, como participante do sistema universitário brasileiro, acaba por incorporar as práticas científicas típicas desse meio. Uma das conseqüências será a busca de qualificação do corpo 
docente dos cursos de graduação em programas de pós-graduação, inicialmente no exterior, mas também, e crescentemente, no Brasil. Um grupo desses docentes optou por buscar os cursos de pós-graduação em educação no Brasil. Principalmente com base nessa influência, o campo da EF passa a incorporar as discussões pedagógicas nas décadas de 1970 e 1980, muito influenciadas pelas ciências humanas, principalmente a sociologia e a filosofia da educação de orientação marxista.

O eixo central da crítica que se fez ao paradigma da aptidão física e esportiva foi dado pela análise da função social da educação, e da EF em particular, como elementos constituintes de uma sociedade capitalista marcada pela dominação e pelas diferenças (injustas) de classe.

Toda a discussão realizada no campo da pedagogia sobre o caráter reprodutor da escola e sobre as possibilidades de sua contribuição para uma transformação radical da sociedade capitalista foi absorvida pela EF. A década de 1980 foi fortemente marcada por essa influência, constituindo-se aos poucos uma corrente que inicialmente foi chamada de revolucionária, mas que também foi denominada de crítica e progressista. Se, num primeiro momento - digamos, o da denúncia -, o movimento progressista apresentava-se bastante homogêneo, hoje, depois de mais de 15 anos de debate, é possível identificar um conjunto de propostas nesse espectro que apresentam diferenças importantes.

O quadro das propostas pedagógicas em EF apresenta-se hoje bastante mais diversificado. Embora a prática pedagógica ainda resista a mudanças, ${ }^{4}$ ou seja, a prática acontece ainda balizada pelo paradigma da aptidão física e esportiva, várias propostas pedagógicas foram gestadas nas últimas duas décadas e se colocam hoje como alternativas. A seguir apresentamos de forma resumida algumas delas. ${ }^{5}$

Uma dessas propostas é a chamada abordagem desenvolvimentista. A sua idéia central é oferecer à criança - a proposta limita-se a oferecer fundamentos para a EF das primeiras quatro séries do primeiro grau - oportunidades de experiências de movimento de modo a garantir o seu desenvolvimento normal, portanto, de modo a atender essa criança em suas necessidades de movimento. Sua base teórica é essencialmente a psicologia do desenvolvimento e da aprendizagem, e seus autores principais são os professores Go Tani e Edison de Jesus Manoel, da USP, e Ruy Jornada Krebs, da UFSM. 
Observe-se que próxima a essa abordagem podemos colocar a chamada psicomotricidade, ou educação psicomotora, que exerceu grande influência na EF brasileira nos anos 70 e 80 . Influência esta que está longe de ter-se esgotado, conforme podemos perceber pela reportagem recente da revista Nova Escola, intitulada "A educação física dá uma mãozinha", na qual se demonstra como a EF pode auxiliar no ensino de matemática (Falzetta 1999). Essa proposta vem sendo criticada exatamente porque não confere à EF uma especificidade, ficando seu papel subordinado a outras disciplinas escolares. Nessa perspectiva o movimento é mero instrumento, não sendo as formas culturais do movimentar-se humano consideradas um saber a ser transmitido pela escola.

A proposta do professor João Batista Freire (Unicamp), embora preocupada com a cultura especificamente infantil, porque fundamentada também basicamente na psicologia do desenvolvimento, pode igualmente ser colocada como próxima às duas anteriores.

Talvez devêssemos também fazer menção a um movimento de atualização ou renovação do paradigma da aptidão física, levado a efeito com base no mote da promoção da saúde. Considerando os avanços do conhecimento biológico acerca das repercussões da atividade física sobre a saúde dos indivíduos e as novas condições urbanas de vida que levam ao sedentarismo, essa proposta revitaliza a idéia de que a principal tarefa da EF é a educação para a saúde ou, em termos mais genéricos, a promoção da saúde.

As propostas abordadas até aqui têm em comum o fato de não se vincularem a uma teoria crítica da educação, no sentido de fazer da crítica do papel da educação na sociedade capitalista uma categoria central. Esse é o caso de duas outras propostas que vão mais explícita e diretamente derivar-se das discussões da pedagogia crítica brasileira.

Uma delas está consubstanciada no livro Metodologia do ensino da educação física, de um coletivo de autores, publicado em 1992. Essa proposta baseia-se fundamentalmente na pedagogia históricocrítica desenvolvida por Dermeval Saviani e colaboradores, e autointitulou-se crítico-superadora. Entende essa proposta que o objeto da área de conhecimento EF é a cultura corporal que se concretiza nos seus diferentes temas, quais sejam, o esporte, a ginástica, o jogo, as lutas, a dança e a mímica. Sistematizando o conhecimento da EF em ciclos ( $1^{\circ}$ - da organização da identidade dos dados da realidade; $2^{\circ}$ 
- da iniciação à sistematização do conhecimento; $3^{\circ}$ - da ampliação da sistematização do conhecimento; 4ํ - do aprofundamento da sistematização do conhecimento), propõe que este seja tratado de forma historicizada, de maneira a ser apreendido em seus movimentos contraditórios.

Outra proposta nesse espectro é a que se denomina críticoemancipatória e que tem como principal formulador o professor Elenor Kunz, da UFSC, hoje acompanhado na tarefa por um conjunto de colegas que compõem o Núcleo de Estudos Pedagógicos do Centro de Desportos daquela universidade. As primeiras elaborações do professor Kunz foram fortemente influenciadas pela pedagogia de Paulo Freire (Kunz 1991). Outra forte influência são as análises fenomenológicas do movimento humano com base, em parte, em MerleauPonty, tomadas de estudiosos holandeses como Gordjin, Tamboer, e também Trebels, este seu orientador no doutorado em Hannover (Alemanha). A proposta de Kunz parte de uma concepção de movimento que ele denomina de dialógica. O movimentar-se humano é entendido aí como uma forma de comunicação com o mundo. Outro princípio importante em sua pedagogia é a noção de sujeito tomado numa perspectiva iluminista de sujeito capaz de crítica e de atuação autônomas, perspectiva esta influenciada pelos estudiosos da Escola de Frankfurt. A proposta aponta para a tematização dos elementos da cultura do movimento, de forma a desenvolver nos alunos a capacidade de analisar e agir criticamente nessa esfera.

É imperioso fazer menção também à proposta da concepção de aulas abertas à experiência, tornada conhecida no Brasil pelo professor alemão Reiner Hildebrandt, que foi professor visitante da UFSM. Essa proposta está consubstanciada principalmente em dois livros: um de autoria do professor Hildebrandt em conjunto com seu colega alemão R. Laging (Hildebrandt e Laging 1986); o outro, resultado da divulgação e do trabalho do professor Hildebrandt no Brasil, o qual foi publicado por dois grupos de estudo, o da UFPE e o da UFSM (Visão Didática 1991).Trabalhando com a perspectiva de que a aula de EF pode ser analisada em termos de um continuum que vai de uma concepção fechada a uma concepção aberta de ensino, e considerando que a concepção fechada inibe a formação de um sujeito autônomo e crítico, essa proposta indica a abertura das aulas no sentido de se conseguir a co-participação dos alunos nas decisões didáticas que configuram as aulas. 
Após esta breve (e insuficiente) descrição das diferentes propostas (não todas) que se colocam como alternativas ao paradigma dominante, gostaria de ressaltar alguns pontos.

Para as teorias progressistas da EF citadas (pedagogia críticosuperadora e crítico-emancipatória), as formas culturais dominantes do movimentar-se humano reproduzem os valores e princípios da sociedade capitalista industrial moderna, sendo o esporte de rendimento paradigmático nesse caso. Reproduzi-los na escola por meio da educação física significa colaborar com a reprodução social como um todo. A linguagem corporal dominante é "ventríloqua" dos interesses dominantes. Assim, ambas as propostas sugerem procedimentos didático-pedagógicos que possibilitem, ao se tematizarem as formas culturais do movimentar-se humano (os temas da cultura corporal ou de movimento), propiciar um esclarecimento crítico a seu respeito, desvelando suas vinculações com os elementos da ordem vigente, desenvolvendo, concomitantemente, as competências para tal: a lógica dialética para a crítico-superadora, e o agir comunicativo para a crítico-emancipatória. Assim, conscientes ou dotados de consciência crítica, os sujeitos poderão agir autônoma e criticamente na esfera da cultura corporal ou de movimento e também agir de forma transformadora como cidadãos políticos.

Vale ressaltar que as propostas buscam ser um "antídoto" para um conjunto de características da cultura corporal ou de movimento atuais que, segundo a interpretação dessas abordagens, por um lado, são produtoras de falsa consciência e, por outro, transformam os sujeitos em objetos ou consumidores acríticos da indústria cultural.

Para realizar tal tarefa é fundamental entender o objeto da EF, o movimentar-se humano, não mais como algo biológico, mecânico ou mesmo apenas na sua dimensão psicológica, e sim como fenômeno histórico-cultural. Portanto, essa leitura ou esse entendimento da educação física só criará corpo quando as ciências sociais e humanas forem tomadas mais intensamente como referência. No entanto, é preciso ter claro que a própria utilização de um novo referencial para entender o movimento humano está na dependência da mudança do imaginário social sobre o corpo e as atividades corporais.

Entendo que essa visão do objeto da EF está alcançando uma quase unanimidade na discussão pedagógica desse campo. Os termos cultura corporal, cultura de movimento ou cultura corporal de movimen- 
to aparecem em quase todos os discursos, embora lhes sejam atribuídas conseqüências pedagógicas distintas.

\section{Desafios das propostas pedagógicas progressistas da educação física}

As propostas pedagógicas progressistas em EF deparam com desafios de várias ordens: desde questões relativas à sua implementação, ou seja, de como fazer com que sejam incorporadas pela prática pedagógica nas escolas, até questões mais teóricas que dizem respeito, por exemplo, às suas bases epistemológicas.

Um desses desafios é conquistar legitimidade no campo pedagógico. Os argumentos que legitimavam a EF na escola sob o prisma conservador (aptidão física e esportiva) não se sustentam numa perspectiva progressista de educação e educação física, mas, ao que tudo indica, hoje também não na perspectiva conservadora. Parece que a visão neotecnicista (economicista) de educação, que enfatiza a preparação do cidadão para o mercado de trabalho, dadas as mudanças tecnológicas do processo produtivo, pode prescindir hoje da EF e não lhe reserva nenhum papel relevante o suficiente para justificar o investimento público - a revitalização do discurso da promoção da saúde é uma tentativa de setores conservadores de legitimar a EF na escola, mas tem pouca probabilidade de encontrar eco, haja vista a crescente privatização, e individualização, da saúde promovida pelo Estado mínimo neoliberal. Além disso, o crescimento da oferta e do consumo dos serviços ligados às práticas corporais fora do âmbito da escola e do sistema tradicional do esporte - como as escolas de natação, academias, escolinhas de futebol, judô, voleibol etc. - permite o acesso à iniciação esportiva, às atividades físicas, sem depender da EF escolar.

Parece-nos mais fácil, paradoxalmente, encontrar argumentos para legitimar a EF (e a educação artística), hoje, na escola, de uma perspectiva crítica de educação. Os argumentos vão na mesma direção do exposto quando apresentamos as propostas progressistas do âmbito da EF. A dimensão que a cultura corporal ou de movimento assume na vida do cidadão atualmente é tão significativa que a escola é chamada não a reproduzi-la simplesmente, mas a permitir que o indivíduo se aproprie dela criticamente, para poder efetivamente exercer sua cidadania. Introduzir 
os indivíduos no universo da cultura corporal ou de movimento de forma crítica é tarefa da escola e especificamente da EF.

Outro ponto que se coloca como um desafio é fazer uma leitura adequada da "política do corpo" (Foucault) ou então de como o "corpo" aparece na atual dinâmica cultural, no sentido mais amplo, com suas intersecções sociais, principalmente na sua função de afirmar, confirmar e reconstruir (porque constantemente contestada) a hegemonia de um projeto histórico, bem como situar o papel da instituição educacional nesse processo.

Embora nossa atenção, como profissionais ligados à EF, esteja mais voltada para a cultura corporal ou de movimento num sentido restrito, para compreender as mudanças que se operam nesse âmbito é preciso analisar também o percurso da "história do corpo".

Podemos constatar, principalmente nas três últimas décadas (a partir dos anos 60), um verdadeiro boom do corpo. Essa (re)descoberta do corpo se dá em várias instâncias e perspectivas e suas razões só podem ser aqui discutidas de forma muito precária. Tal (re)descoberta está presente também no meio acadêmico, onde o corpo passa a ser objeto privilegiado da história, da filosofia, da antropologia, da psicologia da aprendizagem etc.

As razões pelas quais o "corpo" - e, por conseqüência, as práticas corporais - passa a ser objeto digno das diversas disciplinas científicas, objeto de atenção da teoria política às teorias da aprendizagem, são, seguramente, múltiplas e complexas. O que é possível afirmar é que estas estão vinculadas ao novo status social que a cultura ocidental vai conferir ao corpo, principalmente a partir da década de 1960.

Sem adotar uma perspectiva internalista nem externalista da história da ciência, é possível dizer que desenvolvimentos internos (conhecimentos do âmbito das ciências cognitivas, da neurofisiologia, da biologia, da filosofia etc.) e externos à ciência (crítica ao caráter repressivo das instituições, a possibilidade da vivência do sexo pelo prazer graças aos avanços da anticoncepção, possibilidades de mercadorização do corpo, o advento da indústria do lazer etc.) levaram a conferir ao corpo ou à dimensão corpórea do homem um significado ou uma importância maior nas teorias explicativas de algumas ciências e a reconhecê-lo como problema ou objeto. Algumas delas possuem importância central para a educação. Refiro-me às teorias da sociologia, da história e da antropologia que enfatizam a importância da ação sobre o corpo como elemento da ordem social, à filosofia, campo em que, depois da crise da ra- 
zão iluminista (paradigma da consciência), percebe-se a retomada do tema da dimensão não-racional do comportamento humano ou da sua dimensão estética; nas teorias da aprendizagem, o corpo passa a ser reconhecido como sujeito epistêmico, pois, como coloca Assmann (1996), "todo conhecimento é um texto corporal, tem uma textura corporal". Enfim, como assevera Eagleton (1998), citado por Alves de Lima (1999), "a retomada da importância do corpo foi uma das mudanças mais importantes no pensamento radical presente".

Mas centrando nossa atenção novamente sobre a dinâmica cultural e sobre como a corporeidade nela se apresenta, seria importante perguntar se está se gestando uma nova visão de corpo (um novo significado humano de corpo), uma visão de corpo que efetivamente supere a visão moderna apresentada aqui e que foi (é?) a base da EF moderna. Em que medida as práticas corporais da atual dinâmica cultural ainda são tributárias fiéis daquela visão moderna de corpo? (corpo-máquina, corpo-ter).

Se estamos num momento de transição na cultura ocidental caminhando para uma cultura pós-moderna -, estamos num campo bastante complexo, indefinido, que não admite simplificações - e que por isso mesmo se coloca como desafio.

Se adotarmos uma postura mais próxima da perspectiva pósmoderna, como, por exemplo, a de Lipovetsky (1989), tenderemos a responder afirmativamente à primeira questão acima. Viver o corpo com base nos valores do presentismo e do narcisismo, sem culpa, e a pulverização radical dos sentidos/significados dessa vivência seriam indicadores do rompimento com valores próprios da modernidade.

Já para Le Breton, hoje realmente há outra visão no discurso que se faz acerca do corpo,

há outra visão, outra atenção, normas sociais modificadas. Neste entusiasmo, se mudou o imaginário do corpo, porém sem que se alterasse o paradigma dualista. Pois não poderia existir uma liberação do corpo e sim uma liberação do homem mesmo, isto é, que significasse para o sujeito uma maior plenitude. E isto através de um uso diferente das atividades físicas ou de uma nova aparência. Separar o corpo do sujeito para afirmar a liberação do primeiro é uma figura de estilo de um imaginário dualista. (1995, p. 138) 
Para o autor, "a paixão pelo corpo modifica o conteúdo do dualismo sem mudar sua forma. Tende a psicologizar o 'corpo-máquina', mas esse paradigma mantém sua influência de forma mais ou menos oculta" (p. 160).

O dualismo de que fala Le Breton é o entre homem e corpo (e não mente-corpo), que tem por base o dualismo homem-natureza. $A$ mercadorização do corpo (técnicas corporais, produtos para o corpo etc.) necessita manter a diferenciação homem-corpo, precisa manter a oposição entre o "que corresponde ao corpo e o que corresponde ao inapreensível do homem" (Le Breton 1995, p. 152).

Courtine (1995, p. 105), analisando o caso dos Estados Unidos, também entende que o momento narcísico do corpo corresponde não a um laisser-aller hedonista, mas a um reforço disciplinar, a uma intensificação dos controles. Ele não corresponde a uma dispersão da herança puritana, mas antes a uma repuritanização dos comportamentos, cujos signos, de modo mais ou menos explícito, multiplicamse hoje.

O desafio se amplia na medida em que essas mudanças ou permanências estão articuladas com as estruturas e os movimentos sóciohistóricos mais amplos que são o alvo, em última instância, das pedagogias progressistas. Essas pedagogias se nutrem de um projeto alternativo de sociedade que precisa se afirmar diante do hoje hegemônico. Daí a importância de uma leitura adequada da realidade que possa se articular com um projeto alternativo realizável.

Outro desafio situa-se no plano mais especificamente epistemológico. É sabido que um movimento, muito influente no momento, questiona fortemente a pretensão de verdade da ciência (ou da razão científica), e com isso acaba atingindo o núcleo central da pedagogia crítica que é exatamente sua pretensão de superar, por meio de uma leitura crítica da realidade (do esclarecimento), a ideologia, superar uma visão superficial, distorcida ou falsa da realidade. Não será possível aqui aprofundar a questão. Mas talvez valha a pena reproduzir ainda um comentário de Tomaz T. da Silva (1993, p. 137), um dos mais importantes teóricos da tradição crítica na educação: "esses questionamentos colocam em questão a própria utilização do termo 'crítico' ou pelo menos nos obriga a repensá-lo. Não creio [diz ele] que haja presentemente alguma resposta fácil a esse importante desafio". 
É claro que os pontos citados não esgotam a agenda das teorias pedagógicas críticas da educação física, embora já constituam uma pauta bastante volumosa.

\section{Notas}

1. Reitemeyer (1987), em seu livro Philosophie der Leiblichkeit (Filosofia da corporeidade), recupera o materialismo radical de L. Feuerbach, mostrando como a dimensão corpórea (a sensibilidade) encontrava na sua visão de mundo uma posição de destaque: "Razão não sensível, não radicada na sensibilidade é (...) irreal, não mais verdadeira, porque não mais orientada para a totalidade e sim para uma metade abstraída da sensibilidade; assim ela não preenche mais os quesitos da razão" (p. 43).

2. O esporte de alto rendimento é de certa forma uma metáfora dessa máxima.

3. Indicações precisas desse processo encontram-se no texto de A. Ferreira Neto, "Pedagogia no exército e na escola: A educação física brasileira (18801950)". Tese de doutorado apresentada para qualificação. Programa de pósgraduação em Educação/Unimep (mimeo.).

4. As razões são muitas e diversas. Vão desde a pressão do contexto cultural e do imaginário social da EF, que persiste e é reforçado pelos meios de comunicação de massa, até o fato de que a formação dos atuais professores de EF ocorreu em cursos de graduação cujo currículo ainda fora inspirado no referido paradigma, passando pelo fato de que as pedagogias progressistas em EF ainda estão em estágio inicial de desenvolvimento.

5. Para uma apresentação mais detalhada, classificando as abordagens em propositivas e não-propositivas, consultar Castellani Filho (1999). Para uma análise crítica das propostas pedagógicas da educação física brasileira construídas na década de 1980, remeto o leitor aos estudos de Caparroz (1997) e Ferreira (1995).

\section{Pedagogical theories cosntitution of phisical education}

ABSTRACT: The present rehearsal analyzes the process of construction of the pedagogic theories of the Physical Education in Brazil, seeking demonstrate how these theories reflect the conception and the meaning body human engendered in modern society. The text presents the pedagogic theories that, in the field of the Physical Education, are placed in a critical perspective in relation to the uses and meanings attributed by the capitalist society to the corporal practices. And, finally, through this discussion, there's a possibility of breaking the modern vision of body, contemplating on the challenges that this transition places for Education and Physical Education. 


\section{Bibliografia}

ALVES DE LIMA, H.L. "Pensamento epistemológico da educação física brasileira: Das controvérsias acerca do estatuto científico". Dissertação de mestrado. Centro de Educação/UFPe, 1999. (Mimeo.)

ASSMANN, H. "Pós-modernidade e agir pedagógico: Como reencantar a educação". Palestra no VIII Endipe. Florianópolis, 1996. (Mimeo.)

BRACHT, V. "A construção do campo acadêmico 'educação física' no período de 1960 até nossos dias: Onde ficou a educação física?". In: Anais do IV Encontro Nacional de História do Esporte, Lazer e Educação Física. Belo Horizonte, 1996, pp. 140-148.

. "Educação física: Conhecimento e especificidade". In: SOUSA, E.S. de e VAGO, T.M. (orgs.). Trilhas e partilhas: Educação física na cultura escolar e nas práticas sociais. Belo Horizonte: Cultura, 1997, pp. 13-23.

CAPARROZ, F.E. Entre a educação física na escola e a educação física da escola. Vitória: CEFD/Ufes, 1997.

CASTELLANI FILHO, L. "A educação física no sistema educacional brasileiro: Percurso, paradoxos e perspectivas". Tese de doutorado. Campinas: Faculdade de Educação/Unicamp, 1999.

COLETIVO DE AUTORES. Metodologia do ensino da educação física. São Paulo: Cortez, 1992.

COSTA, L.P. da. Diagnóstico de educação física/desportos no Brasil. Rio de Janeiro: Ministério da Educação e Cultura: Fundação Nacional de Material Escolar, 1971.

COURTINE, J.-J. "Os stakhanovistas do narcisismo". In: SANT'ANNA, D.B. de (org.). Políticas do corpo. São Paulo: Estação Liberdade, 1995, pp. 81-114.

FALZETTA, R. "A educação física dá uma mãozinha". Revista Nova Escola, mar. 1999.

FARIA FILHO, L.M. de. "História da escola primária e da educação física no Brasil: Alguns apontamentos". In: SOUSA, E.S. de e VAGO, T.M. (orgs.). Trilhas e partilhas; educação física na cultura escolar e nas práticas sociais. Belo Horizonte: Cultura, 1997, pp. 43-58.

FERREIRA, M.G. "Teoria da educação física: Bases epistemológicas e propostas pedagógicas”. In: FERREIRA NETO, A.; GOELLNER, S.V. 
e BRACHT, V. (orgs.). As ciências do esporte no Brasil. Campinas: Autores Associados, 1995.

FOUCAULT, M. Microfísica do poder. $5^{\mathrm{a}}$ ed. Rio de Janeiro: Graal, 1995.

GIL, J. Monstros. Lisboa: Quetzal, 1994.

GONÇALVES, J.A.P. Subsídios para implantação de uma política nacional de desportos. Brasília, 1971.

GRIESWELLE, D. Sportosoziologie. Stuttgart: Kohlhammer, 1978.

GRUPO DE TRABALHO PEDAGÓGICO (UFPE/UFSM). Visão didática da educação física. Rio de Janeiro: Ao livro técnico, 1991.

HILDEBRANDT, R. e LAGING, R. Concepções abertas no ensino da educação física. Rio de Janeiro: Ao Livro Técnico, 1986.

KUNZ, E. Educação física: Ensino \& mudanças. ljuí: Unijuí, 1991.

LE BRETON, D. Antropologia del cuerpo y modernidad. Buenos Aires: Nueva Visión, 1995.

LIPOVETSKY, G. A era do vazio. Lisboa: Antropos, 1989.

REITEMEYER, U. Philosophie der Leiblichkeit. Frankfurt: Suhrkamp, 1988.

RIGAUER, B. Sport und Arbeit. Frankfurt: Shuskamp, 1969.

SANTIN, S. Educação física: Da alegria do lúdico à opressão do rendimento. Porto Alegre: Edições EST/Esef, 1994.

SILVA, T.T. da. "Sociologia da educação e pedagogia crítica em tempos pós-modernos". In: SILVA, T.T. da (org.). Teoria educacional crítica em tempos pós-modernos. Porto Alegre: Artes Médicas, 1993.

SOARES, C.L. "Imagens do corpo 'educado': Um olhar sobre a ginástica no século XIX". In: FERREIRA NETO, A. (org.). Pesquisa histórica na educação física. Vitória: CEFD/Ufes, 1997, pp. 5-32.

SOBRAL, F. Para uma teoria da educação física. Lisboa: Diabril, 1976.

"Cientismo e credulidade ou a patologia do saber em ciências do desporto". Revista Brasileira de Ciências do Esporte, 17(2), 1996, pp. 143-152.

VEIGA NETO, A.J. da. "Currículo, disciplina e interdisciplinaridade". Revista Brasileira de Ciências do Esporte, 17(2), 1996, pp. 128-137.

WELSCH, W. Unsere postmoderne Moderne. Weinheim: Acta Humaniora, 1988. 